\title{
ACESSO, VÍNCULO E ADESÃO AO TRATAMENTO PARA TUBERCULOSE SOB A ÓTICA DE USUÁRIOS E FAMILIARES
}

\author{
Danyllo do Nascimento SILVA JUNIOR ${ }^{1}$ \\ Yago Rodrigues SILVA ${ }^{1}$ \\ Ana Karina Vidal SILVA ${ }^{1}$ \\ Fernanda Aparecida de Queiroz LIMA ${ }^{1}$ \\ Ellany Gurgel Cosme do NASCIMENTO²
}

\begin{abstract}
${ }^{1}$ Acadêmico do Curso de Graduação em Enfermagem, Campus Avançado "Prof ${ }^{a}$ Maria Elisa de Albuquerque Maia" - CAMEAM/UERN, Pau dos Ferros/RN.

${ }^{2}$ Enfermeira, Docente do Curso de Graduação em Enfermagem da Universidade do Estado do Rio Grande do Norte - UERN, Campus Avançado Prof ${ }^{a}$ Maria Elisa de Albuquerque Maia CAMEAM, Departamento de Enfermagem.
\end{abstract}

Autor para correspondência:

Ellany Gurgel Cosme do Nascimento, Rua Lino Guerra, 88, Bairro Dr ${ }^{\circ}$ Sebastião Maltez, Caraúbas/RN, CEP 59780-000, Brasil. E-mail: ellanygurgel@ hotmail.com

Recebido em: 30/05/2014 - Aprovado em: 25/09/2014 - Disponibilizado em: 15/12/2014

\begin{abstract}
RESUMO: Objetivou-se conhecer a realidade dos usuários que aderiram ao tratamento da tuberculose (TB) na cidade de Pau dos Ferros/RN, identificando os fatores que contribuíram para a adesão à terapêutica. Trata-se de uma pesquisa qualitativa, com abordagem exploratória. A coleta de dados se deu por meio de entrevistas semiestruturadas realizadas com usuários e familiares em suas residências no período de fevereiro a março de 2014. Para análise dos dados, realizou-se a leitura e releitura do material obtido nas entrevistas e utilizou-se o método de análise temática, sendo elaboradas sete categorias. Identificou-se como fatores contribuintes para a adesão do usuário ao tratamento para tuberculose, a boa assistência prestada pelas Unidades Básicas de Saúde, orientações satisfatórias dos profissionais, o apoio familiar e o cuidado, sobretudo materno, bem como o pensamento de não desistir do tratamento, mesmo com o surgimento de reações adversas. Apesar de todos os usuários em estudo terem aderido e concluído o tratamento, captouse, mediante os discursos, alguns entraves que tendem a dificultar a adesão. Portanto, faz-se necessário a realização de novas pesquisas qualitativas que venham qualificar a assistência prestada pelos serviços de saúde no tocante ao tratamento para TB.
\end{abstract}

PALAVRAS-CHAVE: Tuberculose; Terapêutica; Assistência Integral à Saúde.

\section{ACCESS, AND RELATIONSHIP ADHERENCE TO TREATMENT FOR TUBERCULOSIS UNDER THE PERSPECTIVE OF USERS AND FAMILY}

\begin{abstract}
This study aimed to know the reality of users who adhered to treatment of tuberculosis ( TB ) in the city of Pau Irons / RN , identifying the factors that contributed to adherence. This is a qualitative study with an exploratory approach . Data collection occurred through semi-structured interviews with patients and families in their homes during the period February to March 2014 . For data analysis, there was reading and rereading the material obtained in interviews and used the method of thematic analysis, being prepared seven categories . It was identified as contributing factors to adhere to their treatment of tuberculosis, the good care provided by the Basic Health Units, satisfactory professional orientation, family support and care, especially breast, and the thought of not abandoning treatment , even with the emergence of adverse reactions . Despite all the users in the study have joined and completed treatment if captured - through speeches, some barriers that tend to hinder adhesion. Therefore, it is necessary to conduct further qualitative research that may qualify the assistance provided by the health services in relation to treatment for TB .
\end{abstract}

KEYWORDS : Tuberculosis ; therapy; Integral Assistance to Health 


\section{INTRODUÇÃO}

A tuberculose (TB) ainda é um dos grandes problemas de saúde pública, tendo em vista que está entre as dez maiores causas de mortalidade no mundo. De acordo com estimativas realizadas pela Organização Mundial da Saúde (OMS), cerca de um terço da população mundial está infectada pelo Mycobacterium tuberculosis, agente causador da tuberculose (Queiroz e Nogueira, 2010).

O Brasil configura-se entre os países com as taxas mais acentuadas de morbimortalidade por tuberculose (Queiroz e Nogueira, 2010), apresentando em 2010 uma taxa de mortalidade de 2,4 por cem mil habitantes e no ano de 2011 uma taxa de incidência $38,3 / 100.000$, sendo que no estado do Rio Grande do Norte (RN) a taxa de mortalidade por Tuberculose no ano de 2010 foi de 1,9/100.000 com taxa de incidência de 31,3/100.000 no RN no ano de 2011(Brasil, 2013).

Apesar da gravidade da doença, a mesma é curável em praticamente $100 \%$ dos casos novos desde que o tratamento quimioterápico seja seguido corretamente (Queiroz e Nogueira, 2010). A quimioterapia é considerada como a principal estratégia de atuação no controle da tuberculose devido à eficácia do tratamento, que segue a lógica de atuar em diferentes estágios do metabolismo bacilar, visando potencializar o efeito no combate à bactéria. No Brasil, os esquemas medicamentosos são padronizados e baseados tanto na forma clínica quanto na história de tratamento anterior. Independentemente do esquema de tratamento utilizado, a medicação é de uso diário (Souza e Silva, 2010).

Entretanto, é necessário agregar ao tratamento medicamentoso conhecimentos sobre os modos de vida de cada usuário, favorecendo o vínculo entre os serviços de saúde e a população, no intuito de retirar o enfoque exclusivo do medicamento e, consequentemente, diminuir as taxas de abandono da terapêutica. O tratamento da tuberculose precisa ser compreendido em sua complexidade e amplitude para alcançar seu sucesso. Nessa perspectiva, apesar da efetividade das drogas contra o bacilo e da estruturação dos serviços de saúde para promover o tratamento, o que vai determinar o êxito terapêutico, ou não, é o comportamento das pessoas (Souza e Silva, 2010).

A OMS conceitua adesão como um processo dinâmico, multifatorial, que conjuga aspectos comportamentais, sociais e psíquicos, que necessita de decisões compartilhadas e corresponsabilidades entre os usuários do serviço, a equipe de saúde e a rede social de apoio, desenvolvido sobre uma abordagem que supra às singularidades socioculturais e subjetivas, objetivando a melhoria da qualidade de vida das pessoas (Souza e col., 2009). 
Nessa ótica, o presente estudo se justifica tendo em vista a necessidade de compreender as ações em torno dessa patologia que afeta diretamente a saúde pública e teve por objetivo conhecer a realidade dos usuários que aderiram ao tratamento da TB na cidade de Pau dos Ferros/RN, identificando os fatores que contribuíram para a adesão à terapêutica.

\section{METODOLOGIA}

Foi realizada uma pesquisa qualitativa, com abordagem exploratória. Realizada no município de Pau dos Ferros, no Estado do Rio Grande do Norte. O município está localizado na Mesorregião do Alto Oeste Potiguar, a uma distância de $400 \mathrm{~km} \mathrm{da}$ capital do Estado, Natal. Com uma área territorial de $259.959 \mathrm{~km}^{2}$, o município conta com 27.745 habitantes, destes 25.551 residem na zona urbana e 2.194 na zona rural (IBGE, 2010). Este município apresenta $100 \%$ de abrangência da Estratégia de Saúde da Família, possuindo um total de 12 Unidades Básicas de Saúde (UBS), sendo 9 localizadas na zona urbana, das quais 3 atendem a zona urbana e rural e 3 unidades localizadas na zona rural (CNES, 2013).

Foram incluídas na pesquisa todas as 9 Unidades Básicas de Saúde pertencentes à zona urbana do município, sendo os sujeitos da pesquisa selecionados mediante o registro de seus nomes no Programa de Controle da
Tuberculose (PCT) e um familiar para cada sujeito selecionado. Utilizaram-se ainda outros critérios de seleção. Critérios de inclusão: a) Usuário cadastrado no PCT e que concluiu o tratamento para Tuberculose; b) Idade superior a 18 anos, tanto para o usuário quanto para o familiar; c) Apresentar condições cognitivas preservadas. Critérios de exclusão: a) Recusa do usuário ou familiar a participar da pesquisa; b) Não concordar com a assinatura do Termo de Consentimento Livre e Esclarecido (TCLE); c) Impossibilidade por algum motivo de participar da pesquisa no momento da coleta de dados.

Inicialmente, procurou-se na Secretaria Municipal de Saúde do município os dados consolidados do total de usuários cadastrados no PCT em cada UBS. A coleta de dados foi realizada no período de fevereiro a março de 2014 por meio de entrevistas semiestruturadas feitas com usuários e familiares, em suas residências. Obtiveram-se os endereços dos sujeitos nas UBS nas quais estavam cadastrados, com a ajuda de profissionais de saúde.

As Unidades de Saúde incluídas no estudo foram: UBS de Pau dos Ferros, UBS Dr. Cleodon Carlos, UBS Dr. Pedro Diógenes Jr., UBS João XXIII, UBS Mãe Cristina, UBS Caetano Bezerra do Nascimento, UBS Vereador João Queiroz de Sousa e UBS São Judas Tadeu, sendo que a sede desta última 
funciona como sendo duas UBS (CNES, 2013).

No total, 31 usuários estavam cadastrados no PCT destas unidades, sendo que 22 concluíram o tratamento. Desses que concluíram, 6 não eram da área da UBS, 1 residia na zona rural, 1 foi a óbito, 1 era criança, 2 recusaram participar da pesquisa, 1 não se conseguiu o contato e 1 estava impossibilitado de participar em virtude de problemas de saúde. Mediante os critérios, 9 no total não participaram da pesquisa. Destes, 3 abandonaram o tratamento, 4 estavam em tratamento, sendo uma criança, 1 cancelou o tratamento porque diagnosticou câncer de pulmão e 1 foi a óbito sem fazer o tratamento. Assim sendo, foram entrevistados 9 usuários que concluíram o tratamento para tuberculose e 7 familiares, uma vez que 2 usuários referiram não terem sido acompanhados por nenhum familiar.

Para análise dos dados, realizou-se a leitura e releitura do material obtido nas entrevistas e utilizou-se o método de análise temática proposto por Minayo (2008), sendo elaboradas categorias. A partir da inferência dos dados, emergiram 7 categorias, quais sejam: Desconhecimento sobre a doença; Perfil socioeconômico e demográfico; Profissão dos usuários; Diagnóstico e tratamento; Tratamento Diretamente Observado; Orientações aos usuários e familiares e Avaliação da assistência no tratamento de TB.
A pesquisa obedeceu à Resolução $\mathrm{n}^{\circ}$ 466/2012 do CNS/MS, foi submetida ao Comitê de Ética em Pesquisa com Seres Humanos da Universidade do Estado do Rio Grande do Norte, sendo aprovada em 03 de setembro de 2013, mediante CAAE 17958313.0.0000.5294. A aceitação dos sujeitos foi efetivada com a leitura e assinatura do Termo de Consentimento Livre e Esclarecido (TCLE), visando garantir a observação dos princípios éticos.

Para preservar a privacidade dos sujeitos, as falas foram identificadas, ao longo do texto, com as letras $\mathrm{U}$ (Usuário) e $\mathrm{F}$ (Familiar), seguidas de algarismos arábicos que representam a ordem das entrevistas.

\section{RESULTADOS E DISCUSSÃO}

Os resultados obtidos pelas entrevistas estão organizados em sete categorias temáticas, sendo estes apresentados concomitantemente com a discussão.

\section{Desconhecimento sobre a doença}

Observou-se, através dos depoimentos dos usuários, que o conhecimento acerca da doença ainda é precário, seja na forma de transmissão, no agente etiológico ou nas condições que favorecem o aparecimento da doença, como revelam as falas dos usuários a seguir: 


\section{[...] Pega até no chinelo! Pega no} chinelo tuberculose, você sabia? (U4)

Sabia que existia, mas não sabia que existia em outras partes do corpo (U7).

O cabra quando tem essas doenças não fica bom de tudo não, melhora, mas não fica como era antes mais não (U8).

Apesar de se tratar de uma doença curável, a tuberculose ainda é marcada pela crença popular de que o usuário com TB nunca fica totalmente recuperado, de que sempre haverá resquícios da doença no seu interior. O doente com "mancha no pulmão" carrega uma marca que altera profundamente sua inserção no grupo social (Pôrto, 2007).

A falta de conhecimento sobre a doença está associada a não adesão ao tratamento, tendo em vista que quanto maior o conhecimento sobre a continuidade do tratamento, maiores são as chances de adesão. Dessa forma, quanto menor o nível de conhecimento referente à continuidade do tratamento, menores são as probabilidades de adesão (Costa e col., 2011).

Todavia, o presente estudo mostra que apesar do conhecimento precário dos usuários, todos progrediram no tratamento e o concluíram. O resultado dessa falta de conhecimento pode ter sido decorrente da ausência de informações mais consistentes por parte do serviço de saúde, contribuindo para a perpetuação de estigmas e preconceitos nessa população.

O desconhecimento sobre a doença não foi perceptível apenas nas falas dos usuários, alguns acompanhantes dos usuários também revelaram sua falta de informação, chegando a desconhecer a própria doença, como se observa no discurso do seguinte familiar.

Não, não foi tuberculose, foi infecção pulmonar, do cigarro (F5).

O conhecimento escasso acerca do tratamento e mesmo das formas de transmissão faz com que o senso comum seja o referencial para o cuidado que realizam inicialmente (Souza e Silva, 2010). Sendo assim, no intuito de conseguir a cura, há a adoção de práticas que podem contribuir para o agravamento ou surgimento de outros problemas de saúde no usuário. Ponto esse que é claramente evidenciado na fala do Familiar 1.

\begin{abstract}
Um dia chegou uma mulher lá em casa, aí ensinou um remédio a ela [avó da usuária], ela tinha que beber um chá de um pinto vivo, mas mata primeiro pra fazer o chá, né?... Aí dela tomar tanto chá e o derradeiro foi o chá desse pinto, a mulher colocou esse
\end{abstract}


pinto dentro do pilão e machucou o pinto, aí botou dentro da água $e$ ferveu, e ela tomou, aí ela num instante estava boa, foi depressa e ela não sentiu mais nunca (F1).

Vale salientar que o trecho anterior retrata uma época marcada por um contexto de dificuldade de acesso aos serviços de saúde, escassez de políticas de saúde pública e dificuldade de diagnóstico, contribuindo assim para adoção de práticas terapêuticas embasadas unicamente no senso comum e sem eficácia comprovada.

No transcorrer de sua história, a representação da TB esteve alicerçada pela marca do preconceito e do estigma, reconhecida como uma doença que vem do outro; do comportamento moralmente condenado; do ar impuro; do local aglomerado; da falta de higiene; daquilo que contagia e do crescimento desestruturado (Clementino e col., 2011).

Nos relatos dos sujeitos da pesquisa, verificou-se que as marcas sociais do estigma e do preconceito ainda estão presentes no cotidiano dos usuários com a doença em questão, gerando angústia e sofrimento. Alguns sujeitos relataram que a doença afetou as relações familiares, principalmente com parentes mais próximos.

Houve sim, meu filho, quando eu estive na casa da minha mãe, aí a minha irmã tinha uma bichinha assim [menina pequena] e disse que não queria nem que a menina ficasse lá, porque sua tia é "tuberculosa", sabe? Aí aquilo eu me senti [...] Aí eu falei: $\hat{O}$ mãe, isso é demais. Eu mesmo, me tocava, não minto pra ninguém não (U8).

Assim que eu recebi a notícia que estava com tuberculose, eu dizia: Eu não acredito que eu estou com tuberculose, tuberculose é doença de quem passa fome. Eu achava que era doença de quem passava fome, que só dava em quem comia mal... (U1).

A doença está atrelada à fome, à ideia de incapacidade de prover recursos mínimos para sua própria sobrevivência ou da família (Pôrto, 2007). A tuberculose faz surgir vários sentimentos que se relacionam diretamente às repercussões da doença sobre o processo de produção social e tudo o que dele pode acontecer (Clementino e col., 2011).

Soma-se a isso, o fato de que, se tratando de uma doença infectocontagiosa, a TB certamente afetará as relações com as pessoas, pois o preconceito ligado ao medo leva a sociedade a se distanciar dos valores pessoais deixando de compartilhar ajuda e solidariedade (Clementino e col., 2011). Apesar de a TB ser uma doença passível de cura, ainda constitui um evento marcante na 
vida da pessoa, revelando que o estigma e o preconceito ainda a acompanham (Hino e col., 2010).

Salienta-se que poucos participantes da pesquisa, de fato, tinham um conhecimento satisfatório sobre a tuberculose (doença, transmissão, tratamento), mesmo tendo vivenciado toda uma terapêutica. Logo, faz-se necessário que os profissionais e os serviços de saúde dispensem maior tempo para os usuários e familiares em geral, com explicações completas e claras sobre a tuberculose e seu tratamento. Sendo que esta proposta apresenta-se como um método eficaz de aumentar os níveis de motivação dos usuários, consequentemente, promovendo a adesão destes ao tratamento (Lewis e Newell, 2009).

\section{Perfil socioeconômico e demográfico}

O nível de instrução dos acompanhantes (familiares) entrevistados pode ser considerado baixo, tendo em vista que cinco relataram possuir o nível de ensino fundamental incompleto, um afirmou ter nível médio incompleto e apenas um acompanhante afirmou ter ensino superior incompleto. Tal resultado se assemelha com os estudos de Queiroz e colaboradores (2012) e Queiroz e Bertolozzi (2010), estes autores associam o baixo nível de escolaridade ao perfil dessa parcela da população, a qual, em geral, não dispõe de excelentes condições de vida, consequentemente, não possuem o acesso adequado aos recursos, dentre os quais, aqueles que se referem à informação. Além disso, vale frisar que o resultado desta categoria associa-se ao fato de que dos sete familiares, quatro já tinham idade avançada e estavam, assim, aposentados. Compreende-se que os aposentados dos dias de hoje, sobretudo de classe social inferior, enfrentaram restrições de acesso ao ensino no passado.

Dos sete familiares, quatro afirmaram que a família já teve pelo menos um caso confirmado de tuberculose, um desses, inclusive, relatou vários casos na mesma família. A possível semelhança das condições de vida pode ter contribuído para a aquisição da patologia.

\section{A família dele [usuário] quase toda já teve $(\mathrm{F} 3)$.}

Há pelo menos 8.000 anos a TB afeta a humanidade. Até a metade do século XIX a doença ainda não era reconhecida como infecto-contagiosa, sendo definida assim em 1882, depois de Robert Koch descobrir o agente causador Mycobacterium tuberculosis. Antes disso, equivocadamente, a doença era atribuída a diversas causas, entre elas, a hereditariedade. Logo, se várias pessoas da mesma família adquirem a doença, provavelmente é em virtude de determinantes 
comuns, que favorecem a sua disseminação (Rodrigues e col., 2007).

\section{Profissão dos usuários}

A maioria dos usuários da pesquisa não exercia nenhum tipo de profissão no momento do tratamento, o que pode ter contribuído para a adesão ao esquema terapêutico, uma vez que os usuários teriam mais disponibilidade para o tratamento. Corroborando com esta afirmativa tem-se o estudo realizado por Queiroz e Bertolozzi (2010) onde se identificou que os usuários que não exerciam atividade laborativa aderiam mais ao tratamento.

São vários os aspectos que envolvem o trabalho exercido pelos usuários, perpassando as esferas econômicas e sociais, tendo em vista que o desligamento das atividades laborativas causa repercussões na subsistência da família. Esse afastamento configura-se como um dos componentes do tratamento, afetando a economia da família e contribuindo, possivelmente, para o abandono da terapêutica. Usuários que exercem atividades de caráter autônomo, em que seus rendimentos econômicos estão diretamente relacionados ao que realizam, como, por exemplo, as atividades comissionadas, são os que mais sofrem (Souza e Silva, 2010).

Tinha gente que ajudava a trazer coisas pra gente, né? Porque ele não podia trabalhar [usuário], ajudava, trazia um alimento, uma coisa (F3).

Esses afastamentos ou mesmo demissões podem causar constrangimentos às pessoas com tuberculose, ao perceberem que estão sendo discriminadas. $O$ que parece motivar essas atitudes é o preconceito atrelado à transmissibilidade e/ou ao estereótipo que a tuberculose carrega, ou seja, é uma doença com alto impacto social, a qual pode atingir até mesmo as relações trabalhistas e as formas de subsistência dos usuários (Souza e Silva, 2010).

Em 2013, eu estava com três meses [na empresa], o cara que eu trabalhava pra ele disse pra mim: $E i$ rapaz, não dá certo você trabalhar aqui, você trabalhar junto com os outros aí e tal, tipo aquele, sabe... tal, aí disse: Está bom (U3).

Assim, percebe-se que o processo de adesão é complexo, ultrapassa o simples ato de ingerir o medicamento, relacionando-se diretamente ao lugar ocupado pelo sujeito no seu processo de produção e reprodução social, ao passo que desse processo surgem as condições favoráveis ou limitantes para a efetivação da manutenção do tratamento (Souza e Silva, 2010). 


\section{Diagnóstico e tratamento}

Desde o período onde ainda não se tinha tratamento até os tratamentos atuais, a TB e suas terapêuticas passaram por significativas transformações, em virtude dos avanços científicos. No Brasil, houve implantação da vacina BCG (1927), políticas de quimioterapia, iniciada com a descoberta da estreptomicina (1944) e o surgimento da resistência bacteriana, a qual levou ao desenvolvimento de vários esquemas terapêuticos. As mudanças não pararam e a década de 70 foi marcada pelo pioneirismo do Brasil em adotar a quimioterapia de curta duração, seis meses, substituindo o esquema anterior de doze meses e que eram realizados até então em hospitais e sanatórios (Hijjar e col., 2007). Falas sobre o avanço científico e um relato de um dos familiares participantes sobre o tratamento que fez para TB na década de 70:

Porque a gente ver, antigamente era uma doença que quase não tinha cura. Aí agora já tem bastante cura, fazendo o tratamento, tomando os remédios direitinho... (F6).

No теи tempo tratamento, meu filho, era um ano, todo dia, eu engolia 25 comprimidos, por uma hora dessas era o tempo que se reunia aquelas pessoas no SESP [atual UBS de Pau dos Ferros], na época nós erámos 18. Aí eles [profissionais de saúde] saíam com os punhadinhos de comprimidos, eram 20 do tamanho de um botão e 5 mais miudinhos. Aí [risos], nós engolia com suco de laranja ou com leite. Isso foi em 70. Durante três meses, 25 comprimidos e uma injeção todo dia, meus braços ficou assim pipinadozinho. Aí... depois de três meses, a gente ficava tomando 5 por dia, só 5 miudinho.[...] Foi um ano, e com um mês, eu não tinha mais nada (F9).

Percebe-se nas falas o entendimento de que houve avanços científicos e que nos dias atuais, fazendo o tratamento corretamente, é possível curar a tuberculose. Entretanto, apesar do progresso, há ainda muitos entraves envolvendo a terapêutica dessa patologia. $\mathrm{O}$ atraso no diagnóstico é um dos maiores. Essa problemática impossibilita a detecção rápida e o precoce início da terapêutica, evitando a disseminação da doença, bem como acaba levando a um uso ineficiente de recursos financeiros escassos pelos usuários (Tadesse e col., 2013). Os discursos a seguir retratam as dificuldades vivenciadas pelos usuários para detectar a TB:

É da anestesia, não é, fazendo Raio X, tratando pneumonia e baixando ao hospital com febre alta e essas coisas, 
foi em torno de quarenta dias [para detectar TB] (U1).

Quando fiz o tratamento mesmo com o infectologista eu já estava com sete meses sofrendo, tomando remédio, gastando, né? Antibióticos tudo caro e não resolvia (U7).

Outro fator que dificulta o diagnóstico precoce de TB é a inadequada sequência de exames seguida por muitos profissionais e os serviços de saúde em geral para o diagnóstico da doença (Ayé e col., 2010). Este fato foi marcantemente evidenciado, mediante as falas:

Febre e perda de peso e uma calor muito grande de noite, e eu perdendo peso e uma tosse, mas não tinha sangue não. Aí eu fui para um médico e ele passou um Raio-X. Aí o Raio-X deu pneumonia grave no pulmão esquerdo, aí foi tratado a pneumonia. [...] Aí o doutor disse: Faça os exames de escarro, aí pronto, eu fui colher, quando eu cheguei lá a bioquímica mesmo que me atendeu, aí ela leu lá as sete laminas todas positivas, aí ela mandou uma funcionária ir lá na minha casa deixar e dizer que começasse o tratamento e rápido porque já estava muito avançado. Eu me tratando de dengue há quarenta dias e deixa que era tuberculose. Teve vários diagnósticos: dengue, pneumonia, pra poder chegar [ao diagnóstico de TB] (U1).

Quando eu fui eu já estava com a certeza, né? Já fui com o Raio-X na mão, já fui com a ordem médica na mão do pneumologista da cidade, da unidade básica, né? Eu estava sentindo tosse seca, febre [...], estava com falta de apetite e... era com falta de apetite, sem coragem, com anorexia, sabe? Com falta de coragem, né? (U2).

O exame baciloscópico do escarro, que classifica o doente como bacilífero, é o método mais eficaz para diagnosticar a TB, já o de cultura é indicado para doentes que continuem com sintomas respiratórios, apesar de duas baciloscopias diretas de escarro negativas. Ao contrário destes, o exame radiológico (Raio-X) pode revelar imagens no pulmão sugestivas de TB, mas não é suficiente para confirmar a doença pulmonar (Brasil, 2013).

Apesar das recomendações do Ministério da Saúde, nota-se pelos discursos anteriores que os profissionais e, consequentemente, os usuários, valorizam erroneamente alguns exames em detrimento de outros, talvez devido a fatores como a complexidade e o custo. Deste modo, o 
diagnóstico, que poderia ser mais rápido, é atrasado e o usuário sofre as consequências desagradáveis, até mesmo graves para o estado de saúde. Salienta-se ainda a incoerência profissional em não associar sintomas clássicos com a TB (Tadesse e col., 2013).

Com relação à quantidade de tratamentos e as influências disto, é fato que pessoas que já fizeram tratamento para tuberculose são mais propensas a não enfrentarem um novo tratamento, por diversos motivos, como por exemplo, o pensamento sobre os efeitos colaterais que irão novamente vivenciar (Neves e col., 2010).

Entre as causas relacionadas ao abandono da terapêutica vale destacar a questão da intolerância medicamentosa (Sá e col., 2007). Esta, particularmente, é uma situação relacionada ao mecanismo de ação do medicamento, mas que também depende da posição que o indivíduo assume durante o tratamento. Assim, ações educativas em saúde de uma maneira geral podem disponibilizar as informações necessárias às pessoas com tuberculose para que enfrentem o processo de adoecimento (Queiroz e Bertolozzi, 2010).

Com a medicação da tuberculose, teve um tipo de medicação que depois eu pesquisei que ela corta o efeito da artrite, do remédio da artrite, aí por isso que eu sentia muitas dores nas articulações, mas por quê? Por que a medicação não fazia efeito, né? Foi tanto que eu passei ainda dois meses depois que eu terminei tudo [tratamento] sentindo muitas dores, aí depois é que foi regularizando, voltou ao normal. Em nenhum momento eu parei, tomava os dois, né? (U2).

Nessa lógica, nota-se a importância da disponibilidade e empatia do profissional de saúde, para que esse consiga entender a experiência vivenciada pelo usuário no momento e saiba encaminhar a situação, fornecendo informações ao mesmo (Queiroz e Bertolozzi, 2010). Tais informações são essenciais para os usuários, uma vez que os medicamentos para TB possuem uma grande capacidade de interação entre si e com outros medicamentos, a exemplo da rifampicina que apresenta grande número de interações medicamentosas, já que pode diminuir a concentração plasmática dos seguintes fármacos, quando administrados concomitantemente: barbitúricos, benzodiazepínicos, bloqueadores betaadrenérgicos, cetoconazol, anticoncepcionais, corticosteroides, dentre outros (Arbex e col., 2010).

Seguir corretamente o tratamento medicamentoso parece ser um dos grandes desafios enfrentados pelos usuários com tuberculose, que informam uma variedade de efeitos colaterais: coceiras pelo corpo, vermelhidão na pele, aumento do apetite, dor 
no estômago, vontade de vomitar, moleza, fraqueza e diarreia. A literatura traz esses efeitos como indesejáveis no tratamento da tuberculose, todavia, na maioria das vezes toleráveis. $\mathrm{O}$ que os incentiva a superar as adversidades envolvidas no processo terapêutico é acreditar na cura, culminando com adesão desses usuários ao tratamento (Souza e Silva, 2010).

Só sentia fome e sono. Era o que dava, o remédio dá fome e sono (U4).

Enjoo. O sol dava irritação na pele e sono nos dois primeiros meses. Se eu ficasse uns cinco minutinhos [exposta ao sol], ficava toda me coçando e dava enjoo, bastante enjoo, parecia que estava grávida [risos] (U7).

Tais reações indesejáveis, que esporadicamente poderiam contribuir para o abandono do tratamento, precisam ser superadas. Dessa forma, essas pessoas sentem-se fortalecidas, adquirem autoconfiança, e se tornam capazes de levar um tratamento extenso e complicado em frente e, por isso, sentem-se vitoriosas (Souza e Silva, 2010).

\section{Tratamento Diretamente Observado}

O Tratamento Diretamente Observado (TDO) ou Tratamento Supervisionado (TS) é uma estratégia recomendada pela Organização Mundial de Saúde (OMS) desde 1993 e visa à supervisão do tratamento do usuário com tuberculose por um profissional de saúde ou familiar. Tal estratégia tem se mostrado bastante eficaz, principalmente porque garante que os medicamentos estão sendo ingeridos corretamente e com a duração apropriada, além de possibilitar, em muitos casos, a aproximação dos profissionais com o contexto social dos indivíduos, estabelecendo, desse modo, vínculos. É altamente recomendado para usuários com dificuldades de adesão (Neves e col., 2010).

Vários estudos recentes têm evidenciado que o TDO é mais eficaz quando supervisionado por um membro da família e não por um profissional de saúde. Experiências feitas mostram que a supervisão de um familiar chega a atingir taxas de cura acima dos $85 \%$ preconizados pelo Ministério da Saúde para o controle da TB (Hino e col., 2012). Todos os sete familiares entrevistados, que melhor acompanharam os usuários no tratamento, eram mulheres. Destas, uma era cunhada, uma esposa, outra irmã e quatro eram mães. Sugere-se com esse resultado que as mulheres, responsáveis por cuidarem da casa e desempenharem o papel de cuidadoras em saúde, representam um fator bastante positivo para a adesão dos usuários à terapêutica, bem como o acompanhamento destes, sobretudo as mães. 
Era cuidando dele pra ele tomar o medicamento bem direitinho, em cima dele. U3, tá na hora de tomar o remédio... (F3).

Eu inventava tudo no mundo pra ela, fazia doce de mocotó, que a gente faz. em casa, num sabe? Aí eu fiz pra ela, isso serviu tanto pra ela, aí ela foi se levantando e se animando. [...] Dentro de casa passava o dia só socada dentro de uma rede, daí eu carreguei ela pra cá [casa da mãe], aí aqui não, ela comia a tempo e na hora. Eu estava presente quando ela tomava [o medicamento], ela preparava $e$ tomava $(\mathrm{F} 1)$.

A supervisão da tomada dos medicamentos não se restringe apenas à mera observação: surge, nesse momento, o vínculo entre o profissional e o usuário, que se mantém, mesmo após o término do tratamento. Os sujeitos da pesquisa admitem ser prazeroso encontrar pessoas que o valorizam e que lhe fornecem um tratamento supervisionado. Em situações de exclusão social, esta parece ser uma oportunidade para sentirem-se valorizados, seguros e cuidados (Queiroz e Bertolozzi, 2010).

Foi maravilhoso. Eu nunca esperava, porque é difícil você encontrar um enfermeiro pra mandar um agente de saúde pra acompanhar sua medicação todo dia (U8).

\section{Orientações aos usuários e familiares}

Considerando que os usuários começam a se sentir melhor após algumas semanas de tratamento e que os medicamentos provocam certos efeitos colaterais, torna-se de suma importância as orientações, tanto para os usuários quanto para seus familiares. Essas orientações devem ser feitas no início do tratamento, abrangendo várias perspectivas, como a doença, seu tratamento, os efeitos indesejáveis e a sugestão de meios para gerenciá-los. Ressaltando que estas ações podem ser realizadas tanto nas visitas dos usuários aos serviços como nas visitas domiciliares feitas pelos profissionais de saúde (Tachfouti e col., 2012).

Dos nove usuários, apenas um relatou que não recebeu orientações $\mathrm{e}$ acompanhamento domiciliar por parte dos profissionais de saúde. Já no que tange às orientações recebidas pelos familiares, dos sete participantes da pesquisa, apenas dois referiram não ter recebido nenhuma orientação. Os números indicam, de certa forma, que as orientações recebidas representam um fator contribuinte para a adesão ao tratamento, uma vez que orientados, eles passam a ter um melhor 
conhecimento sobre a doença e as formas de enfrentá-la.

Não deram orientação. Eu tinha cuidado, eu que tinha por minha conta. Não foi ninguém que veio aqui pra me dizer, eu separei o prato dela, separei o copo dela $(\mathrm{F} 1)$.

Toda vida ela dizia bem direitinho como era pra fazer. Dizia que tinha que fazer o tratamento bem direitinho, tomar o medicamento bem certinho, que não era pra ele [usuário] fumar, nem pra ele beber e era assim (F3).

Aqui ninguém orienta, se você for perguntar, muitas vezes eles querem achar que você quer saber mais que o profissional. Está entendendo? Uma vez eu até falei, num negócio da prefeitura, que a falta de informação leva muita gente a andar mais, porque se for atrás de uma informação, passa por 10 setores para encontrar (F9).

A importância das orientações dadas pelos profissionais é corroborada em estudo feito por Hino e colaboradores (2012) com profissionais de saúde, estes consideraram que o diálogo contínuo com os usuários com TB e seus familiares, no qual orientam, esclarecem dúvidas, propicia a formação de vínculo, o que é imprescindível para o êxito desse cuidado. Os profissionais destacaram ainda a importância do acesso dessas pessoas ao conhecimento sobre a doença, tratamento e outros recursos disponíveis para o controle da enfermidade, através de ações com os comunicantes, objetivando atribuir-lhes responsabilidade pela própria saúde e impedindo a disseminação da doença.

Esse vínculo entre usuário e profissional de saúde torna-se fundamental, o profissional passa a conhecer melhor $\mathrm{o}$ contexto no qual o usuário está inserido, o que pode facilitar a emergência de atitudes que favoreçam a adesão dos indivíduos, uma vez que grande parte das pessoas que tem TB apresenta algum grau de exclusão social (Queiroz e Bertolozzi, 2010).

No começo eu fiquei muito nervosa, né? Mas aí depois ENFERMEIRA disse: Não isso não é nada demais, não. Eu tinha medo, teve até um dia que disse eu vou é me embora porque eu tenho um menino pequeno, que eu não quero adoecer e nem o menino adoecer, daí ENFERMEIRA começou, não tem isso não, a partir de quinze dias tomando o medicamento não corre risco nenhum, aí eu me acalmei (F3).

A educação em saúde é uma importante estratégia para diminuir os abandonos do tratamento, tendo em vista que 
a falta de informação ou a sua inadequada assimilação contribui para uma ingesta não apropriada da medicação e/ou interrupção do tratamento. Assim, o fornecimento de informação ao usuário favorece o autocuidado (Sá e col., 2007).

Outro fator que certamente influenciou positivamente na adesão dos usuários participantes da presente pesquisa ao tratamento diz respeito à distância entre as residências destes e as Unidades Básicas de Saúde. Todos os participantes moram próximos às UBS, considerando a distância sendo percorrida em menos de 15 minutos a pé.

Paz e colaboradores (2012) e Arakawa e colaboradores (2011) discutem que a distância entre a residência e o serviço de saúde pode ser considerado um fator limitante para a adesão, estando uma distância grande implicando na utilização de um transporte motorizado e podendo gerar gastos e perda de tempo. Nessa perspectiva, as lacunas na acessibilidade dos usuários em tratamento prejudicam a qualidade da assistência.

\section{Avaliação da assistência no tratamento de TB}

Dos nove usuários participantes do estudo, apenas um não disse que o atendimento foi bom ou ótimo. Em relação aos familiares, todos afirmaram que $\mathrm{o}$ atendimento foi bom ou ótimo e três ressaltaram que isso foi só durante o tratamento para TB do usuário, excetuando outros momentos. Tais resultados associam-se ao fato de que todos os participantes da pesquisa aderiram ao tratamento. A seguir, algumas falas que elucidam esta categoria.

\begin{abstract}
Foi ótimo. Eles vinham aqui, olhar como era que estava. Enfermeira, agente de saúde, sempre vem, até no tempo do tratamento, sempre vieram (U6).
\end{abstract}

Ah, durante o tratamento foi bom, traziam a medicação nos dias certos, faziam visitas, perguntavam se ela estava sentindo alguma coisa, foi ótimo. Agora antes... (F7).

É imprescindível que a assistência prestada pelos serviços de saúde aos usuários acometidos por TB seja de qualidade, em todas as etapas do processo, seja no acolhimento, no respeito às suas necessidades, privacidade, assistência social, entre outros. Para tanto, torna-se essencial uma equipe de saúde multiprofissional, para que juntos, profissionais e usuários, possam tratar a doença e recuperar a boa saúde. Não há dúvidas de que uma boa assistência favorece a adesão do usuário com TB à terapêutica (Neves e col., 2010). 


\section{CONSIDERAÇÕES FINAIS}

O estudo demonstrou que há vários fatores que contribuem para a adesão do doente ao tratamento de TB. No geral, usuários e familiares classificaram positivamente a assistência prestada pelas UBS durante o tratamento, considerando que as orientações dos profissionais foram satisfatórias. Notou-se ainda que o apoio familiar e o cuidado, sobretudo materno, foram decisivos para o êxito da terapêutica. Além disso, o fato de todos os usuários não terem pensado em desistir do tratamento, mesmo com o aparecimento de poucas e fracas reações adversas, também representa um ponto contribuinte para a cura da doença.

Salienta-se entraves identificados, como o desconhecimento acentuado de usuários e familiares sobre a doença, mesmo

\section{REFERÊNCIAS BIBLIOGRÁFICAS}

ARAKAWA T. et al. Acessibilidade ao tratamento de tuberculose: avaliação de desempenho de serviços de saúde. Rev. Latino-Am. Enfermagem, Ribeirão Preto, 2011. Disponível em: <http://dx.doi.org/10.1590/S0104$11692011000400019>$. Acesso: 4 abr. 2014.

ARBEX, M. A. et al. Drogas antituberculose: interações medicamentosas, efeitos adversos e utilização em situações especiais. Parte 1: vivenciando o tratamento; o fato de ter um usuário que realizou o tratamento com a utilização de bebidas alcoólicas, o que denota uma falta de acompanhamento e conscientização por parte dos serviços. Também a separação de objetos, muito constatado na presente pesquisa e que ajuda a perpetuar estigmas e tabus.

Há possíveis fatores que podem ter interferido nos resultados deste estudo, como viés de memória, tendo em vista que a maior parte dos usuários terminou o tratamento há mais de três anos, o fato de alguns usuários estarem minimamente alcoolizados no momento da coleta de dados e o tamanho reduzido da amostra, apesar de se tratar de todos os usuários que estavam cadastrados no PCT da zona urbana do município e que concluíram o tratamento.

fármacos de primeira linha. J. bras.pneumol., São Paulo, 2010. Disponível em: $<$ http://dx.doi.org/10.1590/S180637132010000500016>. Acesso: 5 abr. 2014. AYÉ, R. et al. Patient's site of first access to health system influences length of delay for tuberculosis treatment in Tajikistan. BMC Health Services Research, 2010. Disponível em: <http://www.biomedcentral.com/14726963/10/10>. Acesso: 26 mar. 2014. 
BRASIL. Ministério da Saúde. DATASUS:

Informações de Saúde. Disponível em:

<http://portalsaude.saude.gov.br/portalsaude/a rquivos/pdf/2013/Mar/25/taxa_incidencia_tub erculose_1990_2012_base_22_02_2013.pdf>. Acesso: 2 abr. 2014.

BRASIL. Ministério da Saúde. DATASUS: Informações de Saúde. Disponível em: $<$ http://portalsaude.saude.gov.br/portalsaude/a rquivos/pdf/2013/Mar/25/taxa_mortalidade_t uberculose_1999_2010_base_22_02_2013.pd f>. Acesso: 2 abr. 2014.

BRASIL. Ministério da Saúde. Tuberculose: perguntas frequentes. Disponível em: $<$ http://www.minsaude.gov.cv/index.php/suasaude/tuberculose>. Acesso: 26 mar. 2014.

\section{CADASTRO NACIONAL DE}

\section{ESTABELECIMENTOS DE SAÚDE}

(CNES). Estabelecimento de Saúde do

Município: Pau dos Ferros. Disponível em:

$<$ http://cnes.datasus.gov.br/Lista_Es_Municip io.asp?VEstado $=24 \&$ VCodMunicipio $=24094$ $0 \&$ NomeEstado=RIO $\% 20$ GRANDE\%20DO \%20NORTE>. Acesso: 25 mar. 2014.

CLEMENTINO, F. S. et al. Tuberculose: desvendando conflitos pessoais e sociais. Rev. enferm. UERJ, Rio de Janeiro, 2011; 19(4):638-43. Disponível em: <http://www.facenf.uerj.br/v19n4/v19n4a23.p df>. Acesso: 5 abr. 2014.

COSTA, S. M. et al. Conhecimento dos clientes com tuberculose pulmonar e seus familiares sobre adesão ao tratamento e fatores associados, no município do Rio Grande (RS). Ciência \& Saúde Coletiva, 2011. Disponível em:

$<$ http://dx.doi.org/10.1590/S141381232011000700078>. Acesso: 5 abr. 2014.

HINO, P. et al. As necessidades de saúde e vulnerabilidades de pessoas com tuberculose segundo as dimensões acesso, vínculo e adesão. Rev. esc. enferm.USP, 2011.

Disponível em:

<http://dx.doi.org/10.1590/S0080-

62342011000800003>. Acesso: 5 abr. 2014.

HINO, P.; TAKAHASHI et al. Conhecimento da equipe de saúde da família acerca das necessidades de saúde das pessoas com tuberculose. Rev. Latino-Am. Enfermagem, 2012. Disponível em: $<$ http://dx.doi.org/10.1590/S010411692012000100007>. Acesso: 27 mar. 2014.

\section{INSTITUTO BRASILEIRO DE}

GEOGRAFIA E ESTATÍSTICA (IBGE). Pau dos Ferros: Infográficos: Dados gerais do município, Censo 2010. Disponível em: <http://cod.ibge.gov.br/236U8>. Acesso: 22 mar. 2014. 
LEWIS, C. P.; NEWELL, J. N. Improving tuberculosis care in low income countries - a qualitative study of patients' understanding of "patient support" in Nepal. BMC Public Health, 2009. Disponível em: $<$ http://www.ncbi.nlm.nih.gov/pmc/articles/P MC2703637/>. Acesso: 30 mar. 2014.

MINAYO, M. C. S. O desafio da pesquisa social. In: MINAYO, M. C. S.; GOMES, S. F. D. R. (orgs.). Pesquisa social: teoria, método e criatividade. $27^{\mathrm{a}}$ ed. Petrópolis: Vozes, 2008.

NEVES, L. A. S.et al. Adesão ao tratamento por indivíduos com a co-infecção HIV/tuberculose: revisão integrativa da literatura. Rev. esc. enferm. USP, 2010. Disponível em: $<$ http://dx.doi.org/10.1590/S008062342010000400041>. Acesso: 26 mar. 2014.

PAZ, L. N. F. Efetividade do tratamento da tuberculose. J. bras. pneumol., 2012.

Disponível em:

$<$ http://dx.doi.org/10.1590/S180637132012000400013>. Acesso: 5 abr. 2014.

PÔRTO, A. Representações sociais da tuberculose: estigma e preconceito. Rev Saúde Pública,São Paulo, 2007. Disponível em: $<$ http://dx.doi.org/10.1590/S003489102007000800007>. Acesso: 5 abr. 2014.
QUEIROZ, E. M.; BERTOLOZZI, M. R. Tuberculose: tratamento supervisionado nas Coordenadorias de Saúde Norte, Oeste e Leste do Município de São Paulo. Rev. esc. Enferm.USP, vol.44, n.2, 2010. Disponível em: <http://dx.doi.org/10.1590/S008062342010000200030>. Acesso: 30 mar. 2014.

QUEIROZ, E. M. et al. Tuberculosis: limitations and strengths of Directly Observed Treatment Short-Course. Rev. Latino-Am. Enfermagem, vol.20, n.2, 2012. Disponível em: <http://dx.doi.org/10.1590/S0104$11692012000200021>$. Acesso: 30 mar. 2014.

QUEIROZ, R.; NOGUEIRA, P. A.

Diferenças na Adesão ao Tratamento da Tuberculose em Relação ao Sexo no Distrito de Saúde da Freguesia do Ó/Brasilândia - São Paulo. Saude soc., São Paulo, 2010.

Disponível em:

<http://dx.doi.org/10.1590/S010412902010000300014>. Acesso: 4 abr. 2014.

RODRIGUES, L. et al. Resposta brasileira à tuberculose: contexto, desafios e perspectivas. Rev. Saúde Pública, vol.41, 2007. Disponível em: <http://dx.doi.org/10.1590/S003489102007000800001>. Acesso: 28 mar. 2014. SÁ, L.D. et al. Tratamento da tuberculose em unidades de saúde da família: histórias de abandono. Texto Contexto Enferm., Florianópolis, 2007. Disponível em: 
<http://dx.doi.org/10.1590/S0104-

07072007000400016>. Acesso: 5 abr. 2014.

SOUZA, M. S. P. et al. Características dos serviços de saúde associadas à adesão ao tratamento da tuberculose. Rev. Saúde Pública, São Paulo, 2009. Disponível em: <http://dx.doi.org/10.1590/S0034$89102009005000085>$. Acesso: 4 abr. 2014.

SOUZA, S. S.; SILVA, D. M. G. V. Passando pela experiência do tratamento para tuberculose. Texto Contexto Enferm, Florianópolis, 2010. Disponível em: <http://dx.doi.org/10.1590/S0104$07072010000400005>$. Acesso: 5 abr. 2014.

TACHFOUTI, N. et al. The impact of knowledge and attitudes on adherence to tuberculosis treatment: a case-control study in a Moroccan region. Pan African Medical Journal, 2012. Disponível em: $<$ http://www.ncbi.nlm.nih.gov/pmc/articles/P MC3428172/>. Acesso: 27 mar. 2014.

TADESSE, T. et al. Long distance travelling and financial burdens discourage tuberculosis DOTs treatment initiation and compliance in Ethiopia: a qualitative study. $B M C$

PublicHealth, 2013. Disponível em: $<$ http://www.biomedcentral.com/14712458/13/424>. Acesso: 26 mar. 2014. 